Shorter communication

\title{
Do motivational interviewing behaviors predict reductions in partner aggression for men and women?
}

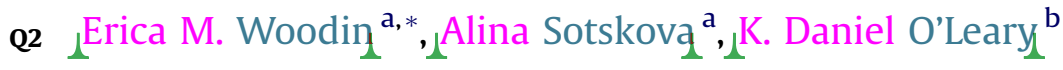 \\ ${ }^{a}$ Department of Psychology, University of Victoria, PO Box 3050 STN CSC, Victoria, British Columbia V8W 3P5, Canada \\ ${ }^{\mathrm{b}}$ Department of Psychology, Stony Brook University, Stony Brook, NY 11794, USA
}

\section{A R T I C L E I N F O}

Article history:

Received 21 May 2010

Received in revised form

1 November 2011

Accepted 2 November 2011

\section{Keywords:}

Motivational interviewing

Therapist competency

Partner aggression

Hierarchical linear modeling

Gender differences

Observational coding

\begin{abstract}
A B S T R A C T
Motivational interviewing is a directive, non-confrontational intervention to promote behavior change. The current study examined therapist behaviors during a successful brief motivational interviewing intervention for physically aggressive college dating couples (Woodin \& O'Leary, 2010). Forty-five minute motivational interviews with each partner were videotaped and coded using the Motivational Interviewing Treatment Integrity scale (MITI; Moyers, Martin, Manuel, \& Miller, 2003). Hierarchical modeling analyses demonstrated that therapist behaviors consistent with motivational interviewing competency predicted significantly greater reductions in physical aggression perpetration following the intervention. Specifically, greater reflection to question ratios by the therapists predicted reductions in aggression for both men and women, greater percentages of open versus closed questions predicted aggression reductions for women, and there was a trend for greater levels of global therapist empathy to predict aggression reductions for women. These findings provide evidence that motivational interviewing seems to have an effect on behavior change through therapist behaviors consistent with the theoretical underpinnings of motivational interviewing.
\end{abstract}

(c) 2011 Elsevier Ltd. All rights reserved.
A commonly cited difficulty in engaging perpetrators of partner aggression in treatment is their unwillingness to accept personal responsibility or to acknowledge the impact of their aggression on their partner (e.g., Pence \& Paymar, 1993). Commonly known as "resistance," behaviors such as anger, irritability, opposition, and suspicion do indeed predict poor response to treatment across a range of disorders (e.g., Beutler, Moleiro, \& Talebi, 2002). Traditional interventions for partner aggression typically target this resistance directly using confrontational interventions to break down resistance and minimization (e.g., Pence \& Paymar, 1993; Saunders, 2000).

Conversely, there is extensive evidence that a positive therapeutic alliance, in which clients are trustful and willing to collaborate, is one of the most important elements of treatment success across a range of interventions (e.g., Lambert \& Barley, 2001), including interventions for partner aggression (Brown \& O'Leary, 2000). Coercive and hostile therapeutic tactics often diminish clients' trust and willingness to collaborate (Ackerman \& Hilsenroth, 2001), potentially limiting treatment effectiveness and

\footnotetext{
* Corresponding author. Tel.: +1 250721 8590; fax: +1 2507218929.

E-mail addresses: ewoodin@uvic.ca (E.M. Woodin), asotskov@uvic.ca (A. Sotskova), k.d.oleary@stonybrook.edu (K.D. O’Leary).
}

possibly even causing harm to vulnerable individuals (Murphy \& Baxter, 1997). In fact, highly resistant individuals tend to be most likely to benefit from client-centered treatment approaches (Beutler et al., 2002).

\section{A motivational interviewing approach to resistance}

Prochaska and DiClemente (1984) proposed a transtheoretical model of change, in which change occurs not as a discrete event but rather as a series of stages: precontemplation, contemplation, preparation, action, and maintenance. From this perspective, reluctance to change is viewed not as a global personal deficit, but rather as an ambivalent state (e.g., contemplation). Based on this model, the goal of intervention with "resistant" clients is to resolve ambivalence and support progression through the stages of change to healthier behavior patterns.

Influenced by the transtheoretical model, Miller (1983) proposed a method for promoting change in problem drinkers, termed motivational interviewing, which emphasizes an empathic, clientcentered approach. Motivational interviewing seeks to enhance individual responsibility and self-efficacy, to avoid confrontation or labeling, to create dissonance between current behavior and beliefs, and to use this dissonance to promote behavior change. As predicted by the transtheoretical model, motivational interviewing 
approaches are particularly effective for heavy drinkers low in readiness to change (Project MATCH Research Group, 1997b). Further, an empathic, client-centered therapeutic style is essential. Similar brief interventions using a directive-confrontational style produce high levels of client resistance that then actually predict increased drinking rates following treatment (Miller, Benefield, \& Tonigan, 1993).

\section{How does motivational interviewing work?}

A key hypothesized mechanism of change in motivational interviewing is an empathic therapeutic stance combined with the use of questions and reflections to facilitate the exploration and resolution of ambivalence and the promotion of behavior change (Miller \& Rollnick, 2002). Therapists display considerable variability in their ability to employ motivational interviewing effectively (e.g., Carroll et al. 2006), and therapist behaviors consistent with motivational interviewing have been shown to be related to the degree of post-intervention behavior change (e.g., Tollison et al. 2008). Thus, therapists' abilities to successfully engage in behaviors consistent with the philosophy of motivational interviewing appear to predict actual client behavior change.

Despite these encouraging findings, no study to date has examined therapists' motivational interviewing competency as a predictor of change for partner aggressive behaviors. Given the similarities between addictive and partner aggressive behaviors in terms of ambivalence and resistance, it seems plausible that motivational interviewing for partner aggression should exhibit similar mechanisms of change.

We currently know very little about how motivational interviewing impacts intact couples, and if men and women in these couples might react differently to motivational interviewing procedures. Meta-analytic findings with other populations suggest that the ratio of men to women in treatment studies does not predict the effectiveness of motivational interviewing (Lundahl, Kunz, Brownell, Tollefson, \& Burke, 2010), providing at least indirect support for the equivalence of the intervention across genders, and data from Project Match indicate no differential effectiveness for a motivational treatment across genders (Project MATCH Research Group, 1997a). We are not aware of any studies that have directly examined the impact of specific therapist behaviors across genders, however, and it is possible that various elements of motivational interviewing may be more or less important for men and women.

This study draws from a randomized controlled trial of partner aggressive dating couples that demonstrated significant reductions in partner aggression perpetration after a 2-h motivational feedback session (Woodin \& O'Leary, 2010). The goal of the current study was to examine the impact of therapists' motivational interviewing behaviors on changes in partner aggression perpetration for men and women in a motivational intervention condition. We hypothesized that therapist behaviors consistent with the tenets of motivational interviewing, including greater global empathy and motivational interviewing spirit, as well as more frequent use of specific motivational interviewing behaviors, such as higher reflection to question ratios, more open than closedended questions, more complex than simple reflections, and more motivational interviewing consistent behaviors, would predict reductions in aggression perpetration for both men and women across the nine months following the feedback session. Further, because a previous study with this sample found that women were more accepting in general of female partner aggression than men were of male partner aggression (Woodin \& O'Leary, 2010), and hence may have particularly benefited from an intervention designed to increase cognitive dissonance and enhance motivation to change, we predicted that women would be more affected than men by proficient motivational interviewing techniques.

\section{Method}

Participants

The 25 couples included in the current study were part of a larger sample of 50 college student couples who received a motivational interviewing intervention as part of a randomized trial of motivational interviewing with physically aggressive dating couples (For a description of the full study procedures, please see Woodin \& O'Leary, 2010). Participants were recruited from Stony Brook University, a state university on Long Island, New York. Advertisements around campus announced a research study for college couples who wanted to "learn more about" their relationships. Couples randomized to the motivational interviewing intervention, but not the control condition, are included in the current study. All procedures were approved by the institutional review board at Stony Brook University.

\section{Eligibility}

Eligibility criteria included being between the ages of 18 and 25, dating for at least three months, no history of marriage or cohabitation, and at least one act of male-to-female physical aggression reported by either partner on the Revised Conflict Tactics Scales (CTS2; Straus, Hamby, Boney-McCoy, \& Sugarman, 1996). The CTS2 was modified to assess for acts of mild physical aggression occurring in the previous three months, and included throwing something that could hurt, twisting an arm or hair, pushing or shoving, grabbing, and slapping.

\section{Participant demographics}

The average relationship length for the 25 couples was 24.72 months $(S D=22.21)$. The average age of women and men was 19.80 $(S D=1.47)$ years and $20.08(S D=1.08)$ years respectively. The median yearly family of origin income was $\$ 70,000$ to $\$ 79,999$ for both women and men. The modal level of completed education for both genders was two years of college. Racial identification was as follows: African American (8\% women, 6\% men); Asian American (44\% women, 42\% men); Caucasian (48\% women, 60\% men); American Indian (0\% women, $6 \%$ men); Native Hawaiian or Pacific Islander ( $0 \%$ women, $6 \%$ men), and Other Race ( $8 \%$ women, $8 \%$ men). Twelve percent of women and $20 \%$ of men identified with more than one race. Measured separately, $12 \%$ of both women and men identified as Hispanic ethnicity.

\section{Procedure}

Eligible couples were first scheduled for a 2-h assessment session to complete questionnaires assessing partner aggression and related risks and consequences of aggression in their current relationship and to complete a conjoint semi-structured interview regarding the course of their relationship. Feedback sessions were then scheduled within several weeks $(M=2.10, S D=1.62)$ of the assessment session, and were delivered by the same therapist who conducted the assessment session. Feedback sessions were videotaped with participants' consent. Finally, participants completed online follow-up questionnaires three, six, and nine months after the feedback session. If at least one partner completed a follow-up, aggression estimates could be computed for both partners. In $88 \%$ of the couples at least one partner completed the 3-month follow-up ( $84 \%$ of women, $62 \%$ of men), $90 \%$ completed the sixmonth (78\% women, 56\% men), and 62\% completed the 9-month (58\% women, $40 \%$ men). 


\section{Motivational feedback intervention}

The motivational interviewing feedback sessions were designed based on brief motivational interventions for problems such as heavy alcohol use (e.g., Marlatt et al.1998) and relationship distress (e.g., Cordova et al., 2005). Therapists began by providing each participant with a two-paged individualized feedback sheet regarding the participant's self-reported levels of aggression (their own and their partners), as well as risk factors (psychological aggression, alcohol use) and consequences of aggression (depression, anxiety, relationship distress). For each domain, feedback provided a definition of each category and documented how the participant's responses compared to averages reported for past college student samples.

Therapists provided this individualized feedback in an empathic and non-confrontational manner, discussed the possible impact of the aggression to the participant and to the relationship, and facilitated a discussion of possible behavior change. Risk factors for aggression were discussed as appropriate. Participants were asked to respond to this feedback, and any statements indicating motivation to change were attended to and reinforced by the therapist. Each individual motivational feedback session was no more than $45 \mathrm{~min}$ in duration, and the order in which partners received feedback was randomly assigned by gender.

The last portion of the feedback session was $15 \mathrm{~min}$ in duration and included both partners, thus no specific mention of individual feedback was made. Instead, the therapist asked the couple to discuss their overall hopes and concerns for their relationship as a way to conclude the session. As the format differed from the individual sessions, with both partners present and no specific feedback delivered, this session is excluded from the current study analyses.

The motivational feedback intervention was originally part of a randomized control trial. Findings from that trial indicated that both men and women in the motivational feedback condition reported significantly less partner aggression across the nine-month follow-up period compared to a brief non-motivational intervention control group (Woodin \& O'Leary, 2010).

\section{Therapists}

Assessment and feedback sessions were conducted by five advanced graduate students in clinical psychology, all of whom were female. The same therapist conducted both the assessment and feedback sessions for each couple. Preparation consisted of $20 \mathrm{~h}$ of training in motivational interviewing theory and techniques conducted by the first author, followed by ongoing supervision and checks of treatment fidelity (Moyers, Martin, Manuel, et al., 2003). A standardized treatment manual was also developed with specific protocols for the motivational feedback sessions (available from the first author upon request).

\section{Measures}

\section{Motivational interviewing competency}

Therapist behaviors during the motivational intervention were coded using the Motivational Interviewing Treatment Integrity Code: Version 2.0 (MITI; Moyers, Martin, Manuel et al., 2003). The MITI is a two-pass coding system that captures the global therapist characteristics of MI spirit and empathy, as well as specific behavior frequencies: giving information; close-ended questions; open-ended questions; simple reflections; complex reflections; MI adherent behaviors (asking permission, affirm, emphasize control, support); and MI non-adherent behaviors (advise, confront, direct).
Table 1

Therapist behaviors in the current study compared to pre-established thresholds for beginning proficiency.

\begin{tabular}{llll}
\hline Skill & $\begin{array}{l}\text { Recommended } \\
\text { threshold }\end{array}$ & $\begin{array}{l}\text { Current study } \\
\text { average }\end{array}$ & $\begin{array}{l}\text { Current study } \\
\text { range }\end{array}$ \\
\hline Global empathy & 5 out of 7 & 6.5 & 5 to 7 \\
Global MI spirit & 5 out of 7 & 6.7 & 5 to 7 \\
Reflections:questions & $1: 1$ & $1: 1.59$ & $1: 0.43$ to $1: 3.61$ \\
\% Open-ended questions & $50 \%$ & $62 \%$ & $22 \%-100 \%$ \\
\% Complex reflections & $40 \%$ & $31 \%$ & $9 \%-70 \%$ \\
\% MI adherent & $90 \%$ & $98 \%$ & $71 \%-100 \%$ \\
\hline
\end{tabular}

Four undergraduate research assistants who were blind to study hypotheses were trained in the MITI until they reached acceptable reliability. All feedback sessions were coded for treatment integrity, and $85 \%$ were also independently coded by a second coder. Intraclass correlation coefficients were in the good to excellent range (0.69-0.92), with the exceptions of MI spirit, which was in the fair range ( 0.51 and 0.55$)$, for men and women respectively. There were no significant differences in therapist behaviors displayed during intervention sessions for men versus women, and therapist behaviors were not significantly related to the level of pretreatment aggression perpetration for either gender.

As reported in the original outcome study (Woodin \& O'Leary, 2010), therapist behaviors during the motivational interventions were compared with beginning proficiency levels for motivational interviewing (Moyers, Martin, Manuel, et al., 2003). Table 1 demonstrates that therapists were able to exceed most criteria, including global empathy and MI spirit levels, reflection to question ratios, percent open-ended questions, and percent motivational interviewing adherence. An exception was the proportion of complex reflections to total reflections, considered the most difficult skill to master (Moyers, Martin, Manuel, et al., 2003).

\section{Partner aggression}

Physical aggression perpetration was assessed with the Revised Conflict Tactics Scales (CTS2; Straus et al., 1996), which assess the frequency of aggression perpetration and victimization in the current dating relationship. The CTS2 was modified to assess for aggression during the previous three months (as opposed to the previous year) so that change across the follow $\mathrm{u}_{\mathrm{Z}}$ periods could be detected. At the assessment time point, individuals and their partners did not differ significantly in their reports of female $(t(48)=0.29, p>.10)$ or male $(t(48)=0.29$, $p>.10)$ aggression perpetration. Thus, at each time point, the higher of the available partners' reports for each aggressive behavior were used to calculate each partner's total aggression perpetration. This procedure is commonly used to account for any tendency of individuals to underreport their own aggression (e.g., Heyman \& Schlee, 1997), and also allowed us to maximize the amount of information available at the follow-up time periods. Internal consistency for the CTS2 was adequate for both men $(\alpha=0.75)$ and women $(\alpha=0.83)$.

\section{Results}

Data were analyzed using hierarchical linear modeling (HLM). For each therapist behavior, a two-level HLM analysis was conducted following procedures developed by Raudenbush, Brennan, and Barnett (1995) for the analysis of dyadic data. First, a trajectory was created for each participant's change over time in partner aggression perpetration. Next, each participant's data were fitted with an intercept and slope. Participants' slopes and intercepts were then modeled separately for men and women within couples. 
Table 2

Motivational interviewing behaviors predicting changes in physical aggression after intervention.

\begin{tabular}{|c|c|c|c|c|c|c|c|}
\hline & \multicolumn{3}{|c|}{ Men } & \multicolumn{3}{|c|}{ Women } & \multirow{2}{*}{$\begin{array}{l}\begin{array}{l}\text { Gender } \\
\text { difference }\end{array} \\
\beta_{\text {Men }}-\beta_{\text {Women }}\end{array}$} \\
\hline & $\beta_{\text {Men }}$ & SE & $r$ & $\beta_{\text {Women }}$ & SE & $r$ & \\
\hline Global empathy & -0.05 & 0.06 & 0.07 & $-0.13^{\dagger}$ & 0.07 & 0.14 & 0.07 \\
\hline Global MI spirit & 0.03 & 0.06 & 0.03 & -0.08 & 0.09 & 0.07 & $0.11^{*}$ \\
\hline $\begin{array}{l}\text { Reflection to } \\
\text { question ratio }\end{array}$ & $-0.16^{* * *}$ & 0.04 & 0.30 & $-0.17^{*}$ & 0.07 & 0.19 & 0.01 \\
\hline $\begin{array}{l}\text { \% Open-ended } \\
\text { questions }\end{array}$ & -0.20 & 0.19 & 0.09 & $-0.61^{*}$ & 0.27 & 0.19 & $0.41^{*}$ \\
\hline $\begin{array}{l}\% \text { Complex } \\
\text { reflections }\end{array}$ & -0.10 & 0.34 & 0.02 & 0.23 & 0.41 & 0.05 & -0.33 \\
\hline \% MI adherence & -0.13 & 0.82 & 0.01 & -0.66 & 1.05 & 0.05 & 0.53 \\
\hline
\end{tabular}

Note. $\beta_{\text {Men }}$ and $\beta_{\text {Women }}$ represent unstandardized estimates for men and women respectively. $\beta_{\text {Men }}-\beta_{\text {Women }}$ represents the difference between male and female coefficients. $r=$ effect size estimate.

${ }^{\dagger} p<.10,{ }^{*} p<.05,{ }^{* *} p<.01,{ }^{* * *} p<<.001$.

Equation (1) demonstrates the general form of the two-level Q1 model:

$$
\begin{array}{cc}
\text { Level } 1: & \left.Y_{i j}=\beta_{1} \text { (male partner }\right)+\beta_{2}(\text { female partner }) \\
& +\beta_{3}(\text { male time })+\beta_{4}(\text { female time })+r \\
\text { Level 2: } & \beta_{1}=\gamma_{10}+\nu_{1} \\
& \beta_{2}=\gamma_{20}+\underline{y_{2}} \\
& \beta_{3}=\gamma_{30}+\underline{y_{3}} \\
& \beta_{4}=\gamma_{40}+\underline{y_{4}}
\end{array}
$$

where $Y_{i j}$ is the level of partner aggression for an individual partner of couple $j$ at time $i ; \beta_{1}$ is the initial level for the male partner of couple $j ; \beta_{2}$ is the initial level for the female partner of couple $j ; \beta_{3}$ is the slope of change over time for the male partner of couple $j$; and $\beta_{4}$ is the slope of change over time for the female partner of couple $j$. The estimation of fixed effects was examined using robust standard errors, which tend to be more stable when the highest level (i.e., couples) has a large number of groups (Raudenbush \& Bryk, 2002). Time was centered so that the intercept corresponded to report of aggression perpetration during the assessment session. The slope corresponded to the amount of linear change in partner aggression perpetration from the assessment to the last follow-up. HLM maximizes power by including data with varying numbers and spacing of assessment, thereby enabling the inclusion of participants who do not complete all follow-up assessments or who complete assessments belatedly (e.g., Raudenbush \& Bryk, 2002).

A preliminary analysis was first conducted to test whether change in physical aggression perpetration across the three followups was curvilinear. The addition of a quadratic term representing curvilinear change across time was not statistically significant, therefore only linear prediction models were examined to test study hypotheses.

Table 2 displays the results of HLM analyses for each dimension of therapist behaviors as predictors of change in physical aggression perpetration across all three follow-up periods following the intervention. Unadjusted effect sizes $(r)$ were also computed using the formula $\sqrt{ }\left(t^{2} /\left(t^{2}+\mathrm{df}\right)\right)$.

First, HLM analyses of the global MITI measures indicated that higher levels of global empathy by therapists were related to marginally greater aggression reductions for women (effect size $[r]=0.14$ ), but not for men and that global MI spirit was unrelated to aggression reductions for both women and men.

Second, specific MI behaviors were examined. Higher reflection to question ratios were related to greater aggression reductions for both men $(r=0.30)$ and women $(r=0.19)$. Further, a higher percentage of open-ended questions were related to greater aggression reductions for women $(r=0.19)$, but not for men.
Neither the percentage of complex reflections nor the percentage of motivational adherent behaviors was related to levels of aggression reduction for either gender.

Potential differences between men and women on the impact of significant therapist behaviors were also examined, using hypothesis testing procedures for HLM6. The percentage of open-ended questions $\left(\beta_{\text {diff }}=0.41, p<.05\right)$ impacted aggression reductions significantly more for women than men, suggesting that women may be more affected than men by the greater use of open rather than closed $_{7}$ ended questions. Because a previous analysis of this sample found that women were significantly more physically aggressive than men at pre-treatment (Woodin \& O'Leary, 2010), we conducted a second analysis in which we added pre-treatment aggression as a covariate to control for this possible confound. The gender difference in the impact of a greater proportion of openended questions remained statistically significant, however, suggesting that pre-treatment differences in aggression do not explain this effect.

Finally, we conducted an exploratory analysis to test whether therapists' motivational interviewing competency was related to follow-up questionnaire completion, using identical HLM analyses with completion as the outcome variable. Therapist competency did not significantly predict follow-up completion rates for either men or women, suggesting that therapist behaviors were unrelated to study retention.

\section{Discussion}

Miller (2000) has suggested that motivational interviewing may operate through a process of "joining up" with an individual in a collaborative manner that is respectful of autonomy and individual choice. Consistent with this conceptualization, therapist behaviors indicative of the philosophy of motivational interviewing were indeed predictive of treatment outcome. Specifically, a balanced use of reflections versus questions predicted significant reductions in physical aggression following the intervention for both men and women, and higher levels of global empathy and greater use of open-ended versus closed-ended questions also predicted greater aggression reductions for women. These findings are consistent with previous studies documenting the necessity of an empathic, non-confrontational therapeutic style in promoting behavior change during motivational interventions (Miller et al. 1993).

The greater use of reflections and open-ended questions and less use of closed-ended questions appeared to be particularly important in predicting behavior change in this study. As noted by Tollison et al. (2008), therapist behaviors such as closed-ended questions, although not necessarily considered MI non-adherent, may still indicate ineffectiveness in the administration of motivational interviewing. Hence, this study provides convergent evidence that an empathic therapeutic stance combined with open-ended opportunities for clients to explore ambivalence and consider change may be important elements in the success of motivational interviewing approaches.

Contrary to hypotheses, however, neither the percentage of complex versus simple reflections nor the percentage of $\mathrm{MI}$ adherent versus non-adherent behaviors predicted reductions in aggression. This finding is not necessarily inconsistent with previous research. Moyers, Miller, and Hendrickson (2005) found that interpersonal skills, such as empathy, were most important in predicting client involvement in the motivational interviewing sessions compared to specific MI skills, such as giving advice with permission, affirming, emphasizing control, open-ended questions, reflections, reframing, or support. Similarly, in a study of motivational interviewing for heavy drinkers, Moyers, Martin, Houck, 
Christopher, \& Tonigan (2009) found that reflective listening in particular was a much stronger predictor of client change talk than other MI consistent skills. It may be that motivational interviewing exerts its most powerful effects through the key Rogerian skills of accurate empathy and reflection, rather than specific therapist behaviors or statements.

Men and women were also affected somewhat differently by the motivational intervention. Despite the fact that therapists were equally likely to use each skill across genders, women were significantly more likely than men to become less aggressive to the extent that therapists used a higher ratio of open to closed-ended questions. These results remained significant even controlling for pre-treatment gender differences in aggression perpetration.

To our knowledge this is the first study to directly examine client gender differences in the effectiveness of motivational interviewing techniques. Our results suggest that women may be particularly likely to benefit from the therapeutic space to explore their own ambivalence. Moreover, a previous study with this sample demonstrated that, compared to men's attitudes towards male partner aggression, women tended to be more accepting in general of female partner aggression (Woodin \& O'Leary, 2010), a result that may reflect less societal disapproval for female physical aggression perpetration. Therapists' use of open-ended questions in the current study may have been particularly beneficial in helping women to identify and explore their ambivalence and to contemplate behavior change, given that women may have been less likely to consider their own behavior as potentially harmful or problematic. Considering the sample size of this study, however, interpretations of this gender difference must be made with caution. In addition, the current study was conducted exclusively with female therapists and as such an alternative explanation for our findings may be that women in our study were simply more receptive or benefited more from working with female therapists. Hence, further research in this area is necessary to examine how men's and women's aggression perpetration are affected by therapists' motivational interviewing behaviors.

The current study has several limitations that should be considered. First, the relatively small sample size of 25 couples and the modest follow-up response rate may have limited our power to detect significant effects; however, all non-significant effects in the current study were below the generally established threshold for a small effect size ( $r=0.10$; Cohen, 1988). Thus, the non-significant findings in this study would be unlikely to be clinically meaningful even with larger sample sizes. Further, the use of two-level hierarchical linear modeling, which allowed us to jointly examine male and female trajectories of change across a nine ${ }_{7}$ month period, enabled us to maximize our power to detect significant longitudinal effects.

Second, several of the MITI codes in our study, most notably the global empathy and MI spirit codes as well as the percent MI adherent behaviors, exhibited somewhat of a ceiling effect that may have hindered our ability to detect significant effects. It is possible that a greater range of therapist behaviors would have yielded additional significant findings.

\section{Study implications}

The current study was the first exploration of therapists' motivational interviewing competency as a predictor of behavior change for partner aggressive men and women. Our findings suggest that therapists' empathy, as well as their use of reflections and open-ended questions, can predict reductions in aggressive behaviors up to nine months after a brief motivational intervention, especially for women. It is also possible that other third variables, such as the degree of resistance or self-change statements made by participants, may have influenced therapist behaviors and also predicted behavior change. Although such sequential behavioral analysis was beyond the scope of this study, these questions should be pursued further with a more detailed microanalytic coding system that taps sequential therapist and client behaviors (e.g., Moyers, Martin, Catley, Harris, \& Ahluwalia, 2003).

Findings from this study provide convergent evidence that the basic elements of motivational interviewing, including global empathy and an open and reflective therapeutic style, appear to be important determinants of behavior change. Further, many of these therapist skills may also be generally useful as building blocks of a strong therapeutic alliance, and hence may not be specific to the effectiveness of motivational interviewing approaches alone. Indeed, training in these basic techniques may be an important component of therapist competency across a range of approaches. Finally, the current findings indicate that aggressive men and women may respond somewhat differently to therapist behaviors during motivational interviewing. Further research is needed to examine potential gender differences in the impact of motivational interviewing behaviors, as well as to understand the mechanisms (such as attitudinal factors) that might explain the differential responses of men and women.

\section{Acknowledgments}

This research was supported by NIMH grant F31MH071047 awarded to the first author and NIMH grant R01HMH057985 awarded to the third author.

Special thanks go to Christopher Murphy for feedback on the design of this project, to study therapists Heather Foran, Anita Jose, Esme Londahl Shaller, Sara Steinberg, and Anna Tverskoy, and to observational coders Yelena Bogdan, Gregory-Allen Mutia, Robyn Odegaard, and Amy Xhengh.

\section{References}

Ackerman, S. J., \& Hilsenroth, M. J. (2001). A review of therapist characteristics and techniques negatively impacting the therapeutic alliance. Psychotherapy: Theory, Research, Practice, Training, 38, 171-185.

Beutler, L. E., Moleiro, C., \& Talebi, H. (2002). Resistance in psychotherapy: what conclusions are supported by research? Journal of Clinical Psychology, 58, 207-217.

Brown, P. D., \& O'Leary, K. D. (2000). Therapeutic alliance: predicting continuance and success in group treatment for spouse abuse. Journal of Consulting and Clinical Psychology, 68, 340-345.

Carroll, K., Ball, S., Nich, C., Martino, S., Frankforter, T., Farentinos, C., et al. (2006). Motivational interviewing to improve treatment engagement and outcome in individuals seeking treatment for substance abuse: a multisite effectiveness study. Drug and Alcohol Dependence, 81, 301-312.

Cohen, J. (1988). Statistical power analysis for the behavioral sciences (2nd ed.). Hillsdale, NJ: Erlbaum.

Cordova, J. V., Scott, R. L., Dorian, M., Mirgain, S., Yaeger, D., \& Groot, A. (2005). The marriage checkup: an indicated preventive intervention for treatment-avoidant couples at risk for marital deterioration. Behavior Therapy, 36, 301-309.

Heyman, R. E., \& Schlee, K. A. (1997). Toward a better estimate of the prevalence of partner abuse: adjusting rates based on the sensitivity of the Conflict Tactics Scale. Journal of Family Psychology, 11, 332-338.

Lambert, M. J., \& Barley, D. E. (2001). Research summary on the therapeutic relationship and psychotherapy outcome. Psychotherapy: Theory, Research, Practice, Training, 38, 357-361.

Lundahl, B. W., Kunz, C., Brownell, C., Tollefson, D., \& Burke, B. L. (2010). A metaanalysis of motivational interviewing: twenty five years of empirical studies. Research on Social Work Practice, 20, 137-160.

Marlatt, G. A., Baer, J. S., Kivlahan, D. R., Dimeff, L. A., Larimer, M. E., Quigley, L. A., et al. (1998). Screening and brief intervention for high-risk college student drinkers: results from a 2-year follow-up assessment. Journal of Consulting and Clinical Psychology, 66, 604-615.

Miller, W. R. (1983). Motivational interviewing with problem drinkers. Behavioural Psychotherapy, 11, 147-172.

Miller, W. (2000). Motivational interviewing: IV. Some parallels with horse whispering. Behavioural and Cognitive Psychotherapy, 28, 285-292.

Miller, W. R., Benefield, R. G., \& Tonigan, J. S. (1993). Enhancing motivation for change in problem drinking: a controlled comparison of two therapist styles. Journal of Consulting and Clinical Psychology, 61, 455-461. 
BRT2447_proof — 18 November 2011 — 6/6

6

E.M. Woodin et al. / Behaviour Research and Therapy xxx (2011) 1-6

631

632

633

634

635

636

637

638

639

640

641

642

643

644

645

646

648
Miller, W., \& Rollick, S. (2002). Motivational interviewing: Preparing people for change (and ed.). New York, NY: Guilford.

Moyers, T., Martin, T., Catley, D., Harris, K. J., \& Ahluwalia, J. S. (2003). Assessing the integrity of motivational interviewing interventions: reliability of the motivetonal interviewing skill code. Behavioural and Cognitive Psychotherapy, 31 177-184.

Moyers, T., Miller, W., \& Hendrickson, S. (2005). How does motivational interviewing work? Therapist interpersonal skill predicts client involvement within motivational interviewing sessions. Journal of Consulting and Clinical Psychology, 73, 590-598.

Myers, T. B., Martin, T., Houck, J. M., Christopher, P. J., \& Tonigan, J. (2009). From insession behaviors to drinking outcomes: a causal chain for motivational interviewing. Journal of Consulting and Clinical Psychology, 77, 1113-1124.

Myers, T. B., Martin, T., Manuel, J. K., \& Miller, W. R. (2003). The motivational interviewing treatment integrity code: Version 2.0. Available on the World Wide Web at. www.motivationalinterviewing.org.

Murphy, C. M., \& Baxter, V. A. (1997). Motivating batterers to change in the treatmint context. Journal of Interpersonal Violence, 12, 607-619.

Pence, E., \& Paymar, M. (1993). Education groups for men who batter: The Duluth model. New York: Springer.

Prochaska, J. O., \& DiClemente, C. C. (1984). The transtheoretical approach: Crossing traditional boundaries of change. Homewood, IL: Dorsey Press.
Project MATCH Research Group. (1997a). Matching alcoholism treatments to client heterogeneity: project MATCH posttreatment drinking outcomes. Journal of Studies on Alcohol, 58, 7-29.

Project MATCH Research Group. (1997b). Project MATCH secondary a priori hypotheses. Addiction, 92, 1671-1698.

Raudenbush, S., Brennan, R., \& Barnett, R. (1995). A multivariate hierarchical model for studying psychological change within married couples. Journal of Family Psychology, 9, 161-174.

Raudenbush, S. W., \& Bryk, A. S. (2002). Hierarchical linear models: Applications and data analysis methods (and ed.). Thousand Oaks, CA: Sage Publications.

Saunders, G. B. (2000). Feminist, cognitive, and behavioral group interventions for men who batter: an overview of rationale and methods. In D. B. Wexler (Ed.), Domestic violence 2000: An integrated skills program for men: Group leader's manual (pp. 21-31). New York: Norton.

Straus, M. A., Hamby, S. L., Boney-McCoy, S., \& Sugarman, D. B. (1996). The revised Conflict Tactics Scales (CTS2): development and preliminary psychometric data. Journal of Family Issues, 17, 283-316.

Tollison, S., Lee, C., Neighbors, C., Neil, T., Olson, N., \& Larimer, M. (2008). Questions and reflections: the use of motivational interviewing microskills in a peer-led brief alcohol intervention for college students. Behavior Therapy, 39, 183-194.

Woodin, E. M., \& O'Leary, K. D. (2010). A brief motivational intervention for physically aggressive dating couples. Prevention Science, 11, 371-383.
649

650

651

652

653

654

655

656

657

658

659

660

661

662

663

664

665

666

Please cite this article in press as: Woodin, E. M., et al., Do motivational interviewing behaviors predict reductions in partner aggression for men and women?, Behaviour Research and Therapy (2011), doi:10.1016/j.brat.2011.11.001 